\title{
European qualitative research: a celebration of diversity and a cautionary tale
}

\author{
Catherine Cassell \\ University of Leeds, UK
}

\begin{abstract}
This contribution aims to highlight the diversity in European qualitative management research as a way of celebrating its ongoing development within Europe. In recognising the strengths that emerge from this diversity in epistemological traditions and methods, attention is drawn to the concerns increasingly expressed by qualitative researchers about growing pressures of standardisation. It is argued that qualitative researchers should take every opportunity to encourage methodological diversity whilst resisting attempts at homogenising the experience and reporting of qualitative management research.
\end{abstract}

\section{Introduction}

The contribution of qualitative research methods to our understanding of organization and management is now accepted (Buchanan and Bryman, 2007), and lately a number of authors have reflected upon the progress that qualitative management research has made into the mainstream (e.g. Bluhm, Harman and Lee, 2012; Symon, Cassell and Johnson, 2016). What is meant by qualitative research is a somewhat 'contested terrain' (Johnson et. al., 2007: 37), indeed as Locke (2003: 19) highlights the domain of qualitative research is plural if not potentially confusing to the newcomer. An all-encompassing definition is provided by Alvesson and Deetz (2000:1) who suggest: “Qualitative research has become associated with many different theoretical perspectives, but it is typically oriented to the inductive study of 
socially constructed reality, focusing on meanings, ideas and practices, taking the native's point of view seriously".

It is important to recognise that whereas there are many commonalities in quantitative methods, there is considerable variety in qualitative management research. Notably for this paper, it is pertinent that the use of qualitative research in North America, Europe and the rest of the world has developed at different rates and been informed by different traditions (Lee and Humphrey, 2006). For example Üsdiken (2014) notes that there is less qualitative research published in US journals than their European alternatives. Bengtsson, Eld and Lind (1997) suggest that the transatlantic gap is also about methodological approaches in that European research is more frequently idiographic and processual whereas in contrast US research is dominated by nomothetic approaches with their emphasis upon quantitative analysis across large samples to test hypotheses. Moreover, we know that there are different traditions of qualitative management research within Europe itself, for example Knoblauch et. al. (2002:2) when discussing the variety of qualitative research in Europe highlight how scientific enterprises such as qualitative research are imprinted by cultures - and not only by 'epistemic cultures', but also by their surrounding institutions, traditions and political as well as economic contexts. They suggest that in the European context this has become particularly visible in countries which have passed through a communist era such as Poland and Slovenia where the impact of the specific national traditions of thinking on qualitative methods can be seen.

In this paper I aim to do two things. The first is to highlight the diversity in European qualitative management research as a way of celebrating its ongoing development within Europe. In recognising the strengths that emerge from this diversity in epistemological 
traditions and methods, the second aim is to draw attention to the concerns increasingly expressed by qualitative researchers about growing pressures of standardisation (Mingers and Willmott, 2013; Symon, Johnson and Cassell, 2016). I conclude by arguing that qualitative researchers should take every opportunity to encourage methodological diversity whilst resisting attempts at homogenising the experience and reporting of qualitative management research

\section{The diversity of European qualitative management research}

Whereas there is considerable consistency in the philosophical roots that underpin quantitative approaches, qualitative methods are informed by a wide range of different epistemological and ontological traditions. European thinkers have been central to the development of these paradigms, for example the role of European critical theorists including Marx, Gramsci, Bordieu and Habermas in underpinning the development of traditions (Hassard and Rowlinson, 2011) which still dominate the field of critical management studies. Whole movements in qualitative research such as postmodernism and post-structuralism have been underpinned by the work of European philosophers such as Foucault, Derrida and Lacan. This diversity in epistemological traditions originating in Europe perhaps partially accounts for the friendliness of European journals to such diverse approaches when compared to the US counterparts (Bluhm et al., 2011).The European openness to qualitative research also extends to the publication of a variety of different methods (Bluhm et al., 2011).

There is also considerable diversity in developments in qualitative research in different parts of Europe. To take some examples, Angermüller (2006) suggests that in France although qualitative approaches are used there is little preference for the term 'qualitative' because it implies that a certain kind of methodology is being privileged over another. This is different 
to Germany where there has long been a clear split between what are seen as hard and soft sciences with a resulting impact on the development of qualitative research (Angermüller, 2006). A somewhat different scenario has occurred in the Ukraine where Baranchenko and Yukhanaev (2013) highlight a number of problems with publishing qualitative research including unfamiliarity with methods; lack of understanding about different philosophies; and history and traditions which focus upon numbers and formulae. The authors suggest that one of the underlying problems to the use of qualitative research is that structural changes in the Ukraine system of higher education have meant that pressure is put on academics to publish in only approved national journals which have been through a rigorous approval procedure with the Ministry of Education. This is similar to the pressures that emerge from journal quality rankings that have been noted elsewhere in Europe (Mingers and Willmott, 2013). As they highlight:

"Given the tradition of positivism and quantitative research methodology together with unwillingness to acknowledge other methodological approaches in the field of business and management research, young academics are faced with an unsurmountable difficulty with using alternative philosophical paradigms and research designs" (Baranchenko and Yukhanaev, 2013: 27)

This is a somewhat different situation to the Italian experience for example where qualitative research has had a long tradition (Bruni and Gobo, 2005).

There has also been an emphasis on different types of methods in different European contexts. For example in the UK classic organizational ethnographies were produced during the 1960's and 1970's (e.g. Lupton, 1963; Benyon, 1973), whereas in Italy ethnography has had an enduringly long tradition (Bruni and Gobo, 2005). Angermüller (2006) highlights how the French have particularly made a major contribution to the development of poststructuralism and discourse analysis through the work of writers like Foucault and Lacan. This diversity is important because as Buchanan and Bryman (2007) highlight, the more recent methodological innovation within the field of management and organizational research 
more generally has been located around qualitative and interpretive methods. There are a variety that could be mentioned here, but particularly pertinent examples are more recent applications of story and narrative analysis to organizational research (e.g.: Beech, 2008; Gabriel and Griffiths, 2004; Ylijoki, 2005; Humphreys and Brown, 2002); developments in discourse and rhetorical analysis (e.g.: Symon, 2008; Jørgensen, Jordan and Mitterhofer, 2012; Shepherd and Challenger, 2013) and the use of visual methods in organizational research (e.g. Davison et al, 2012).

Hence the European tradition of qualitative research can be characterised as being informed by a range of different philosophical underpinnings; a variety of methods and a history of methodological innovation and different sets of epistemic and methodological traditions across the continent. Why is this diversity important? My argument is that methodological pluralism offers a wider range of opportunities for investigating different types of research questions hence presenting more opportunities for insights into different managerial phenomena. Therefore any methodological restrictions would only serve to limit our potential for understanding the complexities of management more generally.

\section{A cautionary tale of standardisation}

Having highlighted the rich diversity of qualitative European research, at this point I wish to highlight a source of concern for qualitative management researchers that relates to a variety of increasing pressures for the standardisation of qualitative research. There is evidence of a move in this direction. For example, in seeking to address the difficulties in publishing qualitative research that have been identified by some qualitative management researchers, a number of editors of esteemed journals have produced guidelines regarding what makes a quality piece of qualitative research. These guidelines usually start from what are perceived 
as common problems in the submissions of qualitative researchers. For example Gephart (2004) identifies these as papers being 'one-off' rather than embedded in ongoing research programmes; lack of adequate literature reviews; failure to state explicit goals or research questions; lack of conceptual definition; under-specification of methodology; and failing to re-visit research questions or goals in the discussion and conclusions sections. Similarly Pratt (2009: 857) identifies some 'dangerous paths' to follow that will 'limit an author's ability to publish her or his qualitative research'. He provides a series of alternative paths to compensate for the lack of a 'boilerplate' or a 'standardized language' for writing up qualitative research. Although these recommendations are there to help qualitative writers, one could argue that such guidelines lead to the production of formulaic pieces of research which can have negative consequences given the diversity of methodological approaches highlighted earlier, a point recognised within the most recent of these editorials from the Academy of Management Journal (AMJ) (see Bansal and Corley, 2012).

Furthermore, potential pressures for standardization are apparent in the recommendations for progress that emerge from those such as Bluhm et. al. (2011). Within that paper the progress that qualitative management research has made during the last ten years is equated with citation counts. Given that papers in the American Academy journals are more highly cited than others, and that these papers are judged to have a greater methodological transparency than their European counterparts, the authors conclude that:

"Given the progress that can be made in qualitative management research through higher standards of transparency of methods and analysis, we recommend that European journals follow the lead of US journals in the adoption of higher standards of methodological description of qualitative research" (Bluhm et al, 2011: 1884).

They conclude, somewhat controversially, that the impact of qualitative management research will be improved by the enhanced standardisation of best practices, as seen in US journals. Such prescriptive types of editorials and articles are critiqued extensively by Symon, 
Cassell and Johnson (2016) who argue that they serve to produce "(inappropriate) homogeneous evaluation criteria" with the consequence of "marginalising alternative perspectives and disciplining individual qualitative researchers into particular normative practices" (Symon, Cassell and Johnson, 2016: 1).

There is a significant tension here that is difficult to resolve. On the one hand editors are seeking to enhance the publication opportunities for qualitative researchers through providing sets of guidelines, whereas on the other there are qualitative researchers seeking to use diverse and innovative methods who are keen to shy away from any potential attempts at methodological standardisation. The contextual background here is also complicated in that in many of the different journal rankings lists that impact upon where authors choose to publish, those journals ranked the highest are North American ones such as the US Academy journals. Indeed Cornellissen et al (2012: 210) in their review of matched pairs of qualitative articles published in UK and US journals suggest that authors in seeking to publish in North American journals engage in a balancing act "seeking to gain legitimacy through a particular way of writing up their qualitative data while at the same time trying to stay true to their own philosophical approach and the original integrity of their research project"'. This has also contributed to the aforementioned North American / European divide in qualitative management research.

The dominance of non-qualitative approaches within North American located journals leads to particular problems for European based qualitative researchers. The pressure to publish in US based journals is one that many Business School academics internationally face and the performative nature of management and organizational research (Bell 2011) places particular institutional pressures on qualitative researchers that have been considered elsewhere (Symon et. al., 2008; Willmott, 2011; Mingers and Willmott, 2013). It would seem then that a potential threat to the diversity of qualitative management research is the establishment of a 
particular form of gold standard of qualitative research equated to that published in US journals. However, as Bluhm et al (2011) do highlight, there is a need for US journals to be more open to a more diverse range of qualitative approaches.

A further concern is the increasing popularity within management research of evidence-based management (e.g. Rousseau, 2006). Qualitative and critical management researchers have highlighted that this can potentially be seen as a threat to methodological pluralism in that what constitutes evidence is a hotly contested topic (Learmonth, 2011). Furthermore, the key methodology used in evidence-based inquiry - the systematic review - tends to select and define as 'good' evidence research based upon traditional positivist informed methodologies such as randomized control trials (Cassell, 2011). This critical view is not shared however amongst all qualitative researchers, indeed as Alasuutari (2010) points out other qualitative researchers have responded to this debate by trying to develop criteria to support qualitative evidence, for example in qualitative health research (Dixon-Woods et al, 2006). It seems that what is important here is seeking alternative definitions of evidence that are informed by qualitative research. As Pascale (2016: 222) suggests:

"Qualitative scholarship in the $21^{\text {st }}$ century needs a concept of evidence that will enable us to account for the systematic construction of both presence and absence in physical, textual and historical spaces. We need a concept of evidence that will enable us to examine contexts as flows of information, relationships, people, ideas and resources".

Hence we need a definition of evidence that is appropriate for qualitative research.

In summary, the key issue here is to ensure that any disciplinary trends do not have an impact upon the acceptance of methodological diversity. Examples range from standardizing the 
content of doctoral programmes to concerns about the governance processes surrounding ethical research (e.g. Bell, 2011; Cassell and Symon, 2012).

\section{Conclusions}

I have drawn attention here to the rich diversity of European qualitative management research and to potential concerns regarding increasing standardisation in the domain. I have argued that methodological diversity and pluralism is something to be cherished offering a variety of insights into a range of different research questions. In concluding, the onus is not just upon qualitative researchers to resist attempts to homogenize qualitative management research and encourage the use of qualitative methods, but also upon epistemological gatekeepers (Symon and Cassell, 1999) such as editors and reviewers to facilitate methodological pluralism. We need an international methodological landscape that reflects and celebrates the diverse traditions that comprise qualitative management research. 


\section{References}

Alasuutari, P. (2012) The rise and relevance of qualitative research. International Journal of Social Research Methodology, 13 (2): 139-155.

Alvesson., M. \& Deetz. S. (2000). Doing critical management research. London: Sage.

Angermüller, J. (2006). "Qualitative" methods of social research in France: reconstructing the actor, deconstructing the subject. Forum: Qualitative Social Research, 6, (3) art. 19. available at: www.qualitative-research.net/fqs-texte/3-05/05-3-34-e.htm (accessed 11th May 2016).

Bansal, T, and Corley, K. (2011). The coming of age of qualitative research: embracing the diversity of qualitative methods. Academy of Management Journal, 54 (2): 233-237.

Baranchenko, Y. and Yukhanaev, A. (2013). Barriers to using qualitative methods in business and management research in the Ukraine. Proceedings of the 12th European Conference on Research Methodology for Business and Management Studies, University of Minho, Guimaraes, Portugal, 4-5 July 2013

Beech, N. (2008). On the nature of dialogic identity work. Organization, 15, $51-74$.

Bell, E. (2011). Managerialism and management research: would Melville Dalton get a job today? In C.M. Cassell and B. Lee (Eds.) Challenges and controversies in management research, London: Routledge.

Bell, E. and Wray Bliss, E. (2009). Research ethics, regulations and responsibilities. In D. Buchanan and A. Byman (Eds.) The Sage Handbook of Organizational Research Methods, London: Sage.

Bengtsson, L., Elg, U. and Lind, J. (1997). Bridging the transatlantic publishing gap: how North American reviewers evaluate European idiographic research. Scandinavian Journal of Management, 13 (4): 473-492.

Benyon, H. (1973). Working for Ford. Harmondsworth: Penguin.

Bluhm, D.J., Harman, W., Lee, T.W. and Mitchell, T.R. (2012). Qualitative research in management: a decade of progress. Journal of Management Studies, 48: 1866-1891.

Bruni, A.and Gobo, G. (2005). Qualitative Research in Italy. Forum: Qualitative Social Research, 6, (3) art. 41. available at:www.qualitative-research.net/fqs-texte/3-05/053-34-e.htm (accessed 11th May 2016).

Buchanan, D.A., and Bryman, A. (2007). Contextualising methods choice in organizational research. Organizational Research Methods, 10, 483-501.

Cassell, C.M .(2011). Evidence-based I-O Psychology: What do we lose on the way?. Industrial and Organizational Psychology: Perspectives on science and practice, 4 (1): 23-26.

Cornellissen, J. Gajewska-de Mattos, H., Piekari, R. and Welch, C. (2012). Writing up as a legitimacy-seeking process. In G. Symon and C.M. Cassell (eds.) Qualitative organizational research: core methods and key challenges, London: Sage. 
Davison, J., McLean, C., and Warren, S. (20120. Exploring the visual in organizations and management. Qualitative research in organizations and management: an international journal, 7(1): 5-15.

Dixon-Woods, M., Bonas S, Booth A, Jones DR, Miller T, Sutton AJ, Shaw RL, Smith JA, Young B. (2006). How can systematic reviews incorporate qualitative research? A critical perspective. Qualitative Research 6 (1): 27-44

Gabriel, Y. and Griffiths, D.S. (2004). Storytelling in organizational research, in Cassell, C.M., and Symon, G. (eds) Qualitative methods in organizational research. London; Sage.

Gephart, R.P .(2004). Qualitative research and the Academy of Management Journal. Academy of Management Journal, 47(4): 454-462.

Glaser, B., and Strauss, A. (1967). The discovery of grounded theory: strategies for qualitative research Chicago: Aldine.

Hassard, J. and Rowlinson, M. (2011). The Potential of Radical Research: Marxism, Labour Process Theory and Critical Management Studies. In C.M. Cassell and B. Lee (Eds.) Challenges and controversies in management research, London: Routledge.

Humphreys, M. \& Brown, A.D. (2002). Narratives of organizational identity and identification: a case study of hegemony and resistance. Organization Studies, 23(3): 421-447.

Hurdley, R. (2010). In the picture or off the wall? Ethical regulation, research habitus, and unpeopled ethnography. Qualitative Inquiry, 16(6) : 517-528.

Johnson, P., Buehring, A., Symon, G. and Cassell, C.M. (2007). Defining qualitative management research. Qualitative research in organizations and management: an international journal, 3 (1): 23-43.

Jørgensen, L. Jordan, S. and Mitterhofer, H. (2012). Sensemaking and discourse analyses in inter-organizational research: a review and suggested advances. Scandinavian Journal of Management, 28, 107-120.

Knoblauch, H., Flick, U. And Maeder, C. (2005). Qualitative research in Europe: the variety of social research. Forum: Qualitative social research, 6(3), art 34., available at: www.qualitative-research.net/fqs-texte/3-05/05-3-34-e.htm (accessed 11th June 2005).

Learmonth, M. (2011). The relationship between evidence and theory in management research. In C.M. Cassell and B. Lee (Eds.) Challenges and controversies in management research, London: Routledge

Lee, B. and Humphrey, C. (2006). More than a numbers game: qualitative research in accounting. Management Decision, 44 (2): 180-197.

Lincoln, Y.S. and Canella, G.S. (2004). Dangerous discourses: methodological conservatism and government regimes of truth. Qualitative Inquiry, 10(1): 5-14.

Locke, K. (2003). Grounded theory in management research. Thousand Oakes, CA: Sage. 
Lupton, T. (1963). On the shop floor: two studies of workshop organization and output. Oxford: Pergamon Press.

Mingers, J. and Willmott, H. (2013). Taylorizing business school research: On the 'one best way' performative effects of journal ranking lists. Human Relations, 66, pp. 10511073.

Pascale, C. (2016). Discourses of the North Atlantic: Epistemology and hegemony. Qualitative Inquiry, 22 (4): 219-227.

Pratt, M.G. (2009). From the editors. For the lack of a boilerplate: tips on writing up (and reviewing) qualitative research. Academy of Management Journal, 52(5): 856-862.

Prichard, C., Sayers, J. And Bathurst, R. (2007). Franchise, margin and locale: constructing a critical management studies locale in Aotearoa New Zealand. New Zealand Sociology, 22(1): 22-44.

Rousseau, D.M.(2006). Is there such a thing as evidence-based management? Academy of Management Review, 31(2): 256-69.

Shepherd, C. and Challenger, R. (2013). Revisiting Paradigm(s) in Management Research: A Rhetorical Analysis of the Paradigm Wars. International Journal of Management Reviews, 15(2): 225-244.

Symon, G. (2008). Developing the political perspective on technological change through rhetorical analysis . Management Communication Quarterly 22(1): 74-98.

Symon, G., Buehring, A., Johnson, P. and Cassell, C.M. (2008). Positioning qualitative research in the academic labour process. Organization Studies, 29 (10): 1315-1336.

Symon, G. and Cassell, C.M. (1999) 'Barriers to innovation in research practice', In M. Pina e Cunha and C.A. Marques (Eds. ) Readings in Organization Science: Organizational change in a changing context, Lisbon: ISPA. (p. 387-398)

Symon, G., Cassell, C.M. and Johnson, P. (2016). Evaluative practices in qualitative management research: a critical review. Paper currently under review.

Üsdiken, B. (2014). Centres and peripheries: Research styles and publication patterns in 'top' U.S. journals and their European alternatives, 1960-2010. Journal of Management Studies, 51, pp. 764-789.

Willmott, H. (2011). Journal list fetishism and the perversion of scholarship: reactivity and the ABS list. Organization, 18 (4): 429-442.

Ylijoki, O. (2005). Academic nostalgia: A narrative approach to academic work. Human Relations, 58 (5): 555-576. 